University of Nebraska - Lincoln

DigitalCommons@University of Nebraska - Lincoln

Publications from USDA-ARS / UNL Faculty

U.S. Department of Agriculture: Agricultural

Research Service, Lincoln, Nebraska

2006

\title{
Attraction of mosquitoes to volatiles associated with blood
}

\author{
S. A. Allan \\ USDA-ARS, sandy.allan@ars.usda.gov \\ Ulrich R. Bernier \\ University of Florida, ubernier@gainesville.usda.ufl.edu \\ Donald Kline \\ USDA-ARS
}

Follow this and additional works at: https://digitalcommons.unl.edu/usdaarsfacpub

Part of the Agricultural Science Commons

Allan, S. A.; Bernier, Ulrich R.; and Kline, Donald, "Attraction of mosquitoes to volatiles associated with blood" (2006). Publications from USDA-ARS / UNL Faculty. 968.

https://digitalcommons.unl.edu/usdaarsfacpub/968

This Article is brought to you for free and open access by the U.S. Department of Agriculture: Agricultural Research Service, Lincoln, Nebraska at DigitalCommons@University of Nebraska - Lincoln. It has been accepted for inclusion in Publications from USDA-ARS / UNL Faculty by an authorized administrator of DigitalCommons@University of Nebraska - Lincoln. 


\title{
Attraction of mosquitoes to volatiles associated with blood
}

\author{
S. A. Allan ${ }^{凶}$, U.R. Bernier, and D.L. Kline \\ Center for Medical, Agricultural and Veterinary Entomology, USDA/ARS, 1600/1700 23rd Dr., \\ Gainesville, FL 32608, U.S.A.
}

Received 20 May 2005; Accepted 29 September 2005

\begin{abstract}
Responses of the mosquitoes Aedes aegypti, Culex quinquefasciatus, and Culex nigripalpus to volatiles and compounds associated with bovine and avian blood that were presented in collagen membranes were evaluated in olfactometer and landing assays. The presence of attractants produced by blood was supported by more attraction of all species to blood than water controls in the olfactometer. Females of Ae. aegypti and Cx. quinquefasciatus were more attracted to bovine blood than to avian blood, but there was no difference in $C x$. nigripalpus responses. In landing assays, significantly more females of all species landed on casings with blood than on water controls. There was no difference in landing of Ae. aegypti on bovine or avian blood. However, significantly more females of $C x$. quinquefasciatus and $C x$. nigripalpus landed on avian blood compared to bovine blood. Blood presented in collagen casings was an effective method for evaluating in-flight attraction and landing in all three species. In the olfactometer, several individual compounds elicited attraction in all species, but none were as attractive as blood for all species. In landing assays, several organic acids and sulfides elicited landing, with Ae. aegypti responding to the greatest number of compounds. These assay methods are effective for evaluation of volatile compounds from blood, and although responses were obtained to several compounds, none were as effective as blood in the olfactometer and landing assays. Journal of Vector Ecology 31(1): 71-78. 2006.
\end{abstract}

Keyword Index: Mosquito, bovine, avian, blood, attraction, Culex, Aedes.

\section{INTRODUCTION}

One of the most critical problems for female mosquitoes is successfully finding a blood meal. Navigation toward potential hosts involves chemical cues, physical cues such as heat and moisture, and visual cues (Clements 1999). These cues may elicit a range of behaviors including flight activation, short- and long-range orientation during flight, landing, probing, and feeding (Galun 1974). While mosquitoes in nature generally feed on a host, not blood directly, blood alone has been recognized to attract mosquitoes (Burgess and Brown 1957, Schaerffenberg and Kupka 1959, Müller 1968, Khan 1977). Constituents in blood are thought to reflect those present in exhaled breath and skin (Bassette et al. 1966, Khan 1977, Sastry et al. 1980). Probing behavior and ingestion of blood by mosquitoes are influenced by blood components such as non-volatile phagostimulants (adenine nucleotides) (Hosoi 1959, Friend and Smith 1977, Friend 1978, Galun 1988). Landing responses have been reported in Anopheles gambiae to oxocarboxylic acids present in sweat but not to other carboxylic acids (Healy and Copland 2000, Healy et al. 2002). Additionally, landings of Anopheles stephensi were reported to volatiles from guinea pig blood, lysine, and cadaverine (Bos and Laarman 1975). Little is known about the influence of blood components on landing responses of Culex mosquitoes, yet this is an essential prelude to successful blood-feeding.

A range of constituents in human blood has been identified (Dimond et al. 1956, Singh and Micks 1957, Issachar et al. 1982, Ashley et al. 1992, Bonin et al. 1992) yet the role of volatile compounds from blood in attracting and eliciting landing by mosquitoes is not well known. Some chemical constituents from blood and serum such as lysine and other amino acids influence the numbers of approaches but not landings of Ae. aegypti and this is thought to be due to the carbon dioxide bound to these compounds (Brown and Carmichael 1961, Lipsitz and Brown 1964). In this preliminary study, we developed an assay for examination of landing responses to chemical standards and examined attraction and landing responses of Ae. aegypti, Cx. quinquefasciatus, and $C x$. nigripalpus to bovine and avian blood to determine if different blood sources influenced these mosquito responses. In addition, two series of individual volatile compounds similar to those identified from blood, carboxylic acids, and sulfides (Sastry et al. 1980, Issachar et al. 1982, Ashley et al. 1992, U. Bernier unpublished data) were evaluated for their attractiveness and landing responses.

\section{MATERIALS AND METHODS}

Aedes aegypti, Culex quinquefasciatus, and Culex nigripalpus were reared in the laboratory using methods described by Gerberg et al. (1994). Adults were maintained in screen cages with a $10 \%$ sugar solution provided continuously. Cages were held at $27-29^{\circ} \mathrm{C}$ and $70-85 \% \mathrm{RH}$ under a photoperiod of 14:10 (L:D) h with the scotophase starting at $1700 \mathrm{~h}$. For bioassays, unfed females 5 to14-daysold were used.

\section{Olfactometer}

To determine if treatments elicited an upwind orientation response, unfed female mosquitoes were tested in a triple- 
cage dual-port olfactometer (Posey et al. 1998). Only one chamber at a time was used for assays. Air flowing through the olfactometer was obtained externally, then charcoalfiltered, humidified, and warmed ( $\left.27 \pm 1{ }^{\circ} \mathrm{C}, 60 \pm 2 \% \mathrm{RH}\right)$. At the beginning of each test, a door was opened to allow air to flow through the ports $(28 \pm 1 \mathrm{~cm} / \mathrm{s})$ into the chamber. This door was closed at the end of a test to trap mosquitoes in the ports to count them. Active and responsive mosquitoes were selected for the tests using a draw box (Posey and Schreck 1981). Each cage was loaded with 70-80 female mosquitoes that were allowed $\sim 60$ min to acclimate. With the initiation of a test, they could follow an upwind plume to the treatment test port, to the control test port, or remain in the chamber. Responses were calculated as the percentage of total mosquitoes tested that were trapped in the treatment port compared to the control port. All treatments were tested simultaneously with a water control. Tests were run for 15 min. Assays with Ae. aegypti were conducted under high light conditions (2,220-2,400 lux) between 1000 and $1700 \mathrm{~h}$. Assays with Culex were conducted under low light conditions (100-150 lux) between 1400 and $1900 \mathrm{~h}$.

\section{Landing bioassays}

Bioassays were conducted in cages $\left(30 \mathrm{~cm}^{3}\right)$ with one side covered with a sleeve and the other end screened. Twenty females that were sugar-starved for $4 \mathrm{~h}$ were placed in each cage and allowed to acclimate for $20 \mathrm{~min}$. When all mosquitoes had landed on the sides on the cage, a treatment was carefully placed through the sleeve in the center of the cage on a Petri dish. Care was taken to not disturb landed mosquitoes. To determine an optimal time-course of assay, observations were made of the numbers of mosquitoes in contact with the casing at $0.5,1,3,5$, and $10 \mathrm{~min}$. Subsequently observations were made at 1 and $5 \mathrm{~min}$. Assays with Ae. aegypti and Culex were conducted under light conditions similar to those described above. When treatments consisted of blood, the percentage of mosquitoes that had fed to repletion at $10 \mathrm{~min}$ was also determined. In landing assays, treatments were presented before or after controls but not simultaneously with controls.

\section{Test materials}

Tests were conducted using defibrinated bovine or avian (chicken) blood to evaluate responses of mosquitoes to blood. Blood was held at $4^{\circ} \mathrm{C}$ in an airtight container until just before use and used for bioassays within 4 days of collection. Blood $(40 \mathrm{ml})$ was placed in a collagen sausage casing (gas permeable) (30 mm diameter) (DeWeid International, San Antonio, TX) (Wirtz and Rutledge 1980) that was tied at both ends, warmed in a water bath to $40^{\circ} \mathrm{C}$, excess water removed with paper towels, and used immediately in tests. Collagen membranes have previously been reported as satisfactory for feeding (Cosgrove et al. 1994) and evaluation of repellents (Cockcroft et al. 1998). Controls were filled with $40 \mathrm{ml}$ of well water and handled similarly. A filled collagen casing was placed on a disposable Petri dish (100 mm diameter) and placed either in the olfactometer port or bioassay cage for testing. Gloves and solvent-cleaned forceps were used to handle all materials (collagen casings, vial caps, Petri dishes, etc.) to reduce contamination with skin compounds.

Chemical standards were obtained from Sigma-Aldrich, (St. Louis, MO) and Acros (Pittsburgh, PA). For olfactometer assays with chemical standards, $200 \mu \mathrm{l}$ or $200 \mathrm{ug}$ of a compound was placed in a vial cap (9 mm x $9 \mathrm{~mm}$ height) set in a disposable $100 \mathrm{~mm}$ diameter Petri dish and placed in the treatment port. For controls, an empty vial cap in a Petri dish was placed in the other port. For landing assays, chemical standards were diluted in either methanol or hexane as appropriate to a concentration of $100 \mathrm{ng} / \mu \mathrm{l}$. For each treatment, $10 \mu \mathrm{l}$ of the test solution was placed on a warmed $\left(40^{\circ} \mathrm{C}\right)$ collagen casing. Treatments were placed on the top central portion of the casing and the solvent allowed to evaporate before placing the casing into the cage. Controls consisted of casings treated with $10 \mu \mathrm{l}$ of solvent only.

Data were arcsine transformed before means were tested by paired t-test $(P<0.05)$.

\section{RESULTS}

In the olfactometer, mosquitoes of all three species were significantly more attracted to the ports containing blood, whether it was bovine or avian blood, than to the corresponding water controls (Table 1). The controls would have presumably provided the same cues of heat and moisture as the blood treatments; however, the greater attraction of the blood treatments indicates that volatile compounds from the blood are released through the casing in sufficient quantities to elicit attraction of host-seeking female mosquitoes in the olfactometer. Attraction of Ae. aegypti was stronger to bovine blood (58.4\%) than to avian blood $(32.3 \%)(t=5.62$, df $=18$, $P<0.001)$. Attraction to water controls was $12-18.6 \%$ and possibly due to cues of heat and moisture. Attraction of $C x$. quinquefasciatus was also stronger to bovine blood (38.4\%) than to avian blood $(9.6 \%)(t=6.41, \mathrm{df}=18, P<0.001)$ and these responses were half or lower than those of Ae. aegypti. Responses to water controls were low (1.6 - 3.4\%) compared to blood. For $C x$. nigripalpus, bovine blood and avian blood were equally attractive (13.3\% and $14.7 \%$, respectively ( $t=$ 0.64 ; $\mathrm{df}=18, P=0.26$ ) with low responses to water controls (0.0-1.7\%).

The landing assays involved initiation of flight from the resting positions on the walls of the cage, orientation in flight, and landing on the filled casings. Initial landing assays with Ae. aegypti and $C x$. quinquefasciatus showed a pattern of increased number of mosquitoes landing over the $10 \mathrm{~min}$ duration of the assay (Figure 1). Landings did not increase after $5 \mathrm{~min}$ and this was the time chosen for observations in subsequent assays. In landing assays, significantly more mosquitoes landed on casings with blood than with water indicating that the blood was providing additional cues than the water controls that resulted in landing (Table 2). Presentation of the blood in collagen casings was clearly effective for eliciting both attraction and landing responses. There was no difference in the number of Ae. aegypti that landed on the bovine and avian blood treatments at $1 \mathrm{~min}(t=$ 1.02, $\mathrm{df}=18, P=0.16)$ and $5 \min (t=0.81$, df $=18, P=$ 
Table 1. Responses of mosquitoes in olfactometer assays to blood or water presented in collagen casings.

\begin{tabular}{|c|c|c|c|c|}
\hline Species & Treatment & Mean \% attracted (SE) & $\mathrm{N}$ & $P$ \\
\hline \multirow[t]{6}{*}{$\overline{A e . \text { aegypti }}$} & Bovine blood & $58.4(3.3)$ & 10 & $<0.001$ \\
\hline & Water & 12.5 (3.5) & & \\
\hline & Avian blood & 32.2 (7.8) & 10 & 0.006 \\
\hline & Water & $2.8(0.8)$ & & \\
\hline & Water & $12.0(2.9)$ & 10 & 0.25 \\
\hline & Water & $18.6(5.1)$ & & \\
\hline \multirow[t]{6}{*}{ Cx. quinquefasciatus } & Bovine blood & $38.3(6.6)$ & 10 & $<0.001$ \\
\hline & Water & $1.6(0.3)$ & & \\
\hline & Avian blood & $9.6(1.4)$ & 10 & 0.016 \\
\hline & Water & $3.4(1.8)$ & & \\
\hline & Water & $3.0(0.9)$ & 10 & 0.19 \\
\hline & Water & $2.1(0.5)$ & & \\
\hline \multirow[t]{6}{*}{ Cx. nigripalpus } & Bovine blood & $13.0(1.4)$ & 10 & $<0.001$ \\
\hline & Water & $0.2(0.2)$ & & \\
\hline & Avian blood & 14.7 (3.8) & 6 & 0.04 \\
\hline & Water & $1.7(1.1)$ & & \\
\hline & Water & $0.2(0.2)$ & 10 & 0.17 \\
\hline & Water & $0.0(0.0)$ & & \\
\hline
\end{tabular}

0.21). Significantly more Ae. aegypti, however, fed on the bovine blood than on avian blood $(t=12.09, \mathrm{df}=18, P<$ $0.0001)$. Significantly more $C x$. quinquefasciatus landed on avian blood treatments compared to bovine blood treatments at $1 \mathrm{~min}(t=3.55, \mathrm{df}=18, P=0.004)$ and $5 \mathrm{~min}(t=3.05, \mathrm{df}$ $=18, P=0.002)$. However, significantly more $C x$. quinquefasciatus fed on bovine blood than avian blood $(t=$ 9.17, $\mathrm{df}=18, P<0.001)$. For $C x$. nigripalpus, however, significantly more mosquitoes landed on avian blood compared to bovine blood at $1 \mathrm{~min}(t=2.02, \mathrm{df}=18, P=$ $0.028)$ and $5 \mathrm{~min}(t=1.76, \mathrm{df}=18, P=0.04)$. Blood-feeding by $C x$. nigripalpus was low (9.7-17.9\%) with no difference in feeding on either blood source $(t=1.54, \mathrm{df}=18, P=0.07)$.

When individual chemicals were tested in the olfactometer, several compounds elicited greater responses than water controls (Table 3). Attraction was significantly greater for Ae. aegypti to blood, acetic acid, lactic acid, carbon disulfide, dimethyl disulfide, and methyl sulfide than to corresponding water controls (paired t-test, $P>0.05$ ). For $C x$. quinquefasciatus, attraction was significant to blood and lactic acid (t-test, $P>0.05$ ). Females of $C x$. nigripalpus responded significantly to blood, myristic acid, dimethyl disulfide, and methyl propyl disulfide (paired t-test, $P>0.05$ ). Of these responses, none of the chemicals elicited responses equal to bovine blood for Ae. aegypti (paired t-tests, $P>0.05$ ) although the largest responses represented 63.6\% (dimethyl disulfide) of the response to blood. Similarly, for $C x$. quinquefasciatus, none of the compounds tested were similar to the size of response to blood (paired t-tests, $P>0.05$ ) and the largest response was $25.8 \%$ (lactic acid) of the responses to blood. For $C x$. nigripalpus, responses compounds represented 27.7\% (myristic acid) and 24.6\% (dimethyl disulfide) of the response to blood. Although significant responses were obtained in the olfactometer to individual chemicals, for the most part, these responses were lower than to blood.

Numerous individual compounds elicited landing responses in cage assays (Table 4). Responses of Ae. aegypti were significantly larger to blood, acetic acid, benzoic acid, butanoic acid, heptanoic acid, 3-methylbutanoic acid, lactic acid, myristic acid, palmitic acid, salicylic acid, stearic acid, carbon disulfide, methyl propyl disulfide, and methyl sulfide compared to untreated water controls (paired t-test, $P>0.05$ ). Female $C x$. quinquefasciatus landed significantly more in response to blood, acetic acid, palmitic acid, stearic acid, dimethyl trisulfide, and methyl propyl disulfide than to water controls (paired t-test, $P>0.05$ ). In comparison, female $C x$. nigripalpus responded significantly to fewer of the compounds tested and included blood, lactic acid, stearic acid, dimethyl trisulfide, ethyl disulfide, and methyl propyl disulfide. None of the individual compounds, however, elicited landing responses similar to blood in any of the three species of 
Table 2. Landing responses of host seeking female mosquitoes in a cage bioassay to blood and water contained in collagen casings. Assays were 5 min in duration and replicated 10 times.

Mean \% landing (SE)

\begin{tabular}{|c|c|c|c|c|}
\hline Species & Treatment & $1 \mathrm{~min}$ & $5 \mathrm{~min}$ & \% blood-fed \\
\hline \multirow[t]{3}{*}{ Ae. aegypti } & Bovine blood & $35.8(5.7)^{*}$ & $83.9(6.3)^{*}$ & $97.9(1.5)$ \\
\hline & Avian blood & $30.5(3.5)^{*}$ & $85.4(2.0)^{*}$ & $41.0(4.5)$ \\
\hline & Water control & $4.3(0.9)$ & 13.5 (3.6) & - \\
\hline \multirow[t]{3}{*}{ Cx. quinquefasciatus } & Bovine blood & $24.7(4.5)^{*}$ & $50.7(7.1)^{*}$ & $62.6(5.2)$ \\
\hline & Avian blood & $39.2(4.1)^{*}$ & $75.8(4.2)^{*}$ & $12.3(1.0)$ \\
\hline & Water control & 3.5 (1.5) & $3.9(1.2)$ & - \\
\hline \multirow[t]{3}{*}{ Cx. nigripalpus } & Bovine blood & $8.7(2.2)^{*}$ & $24.1(2.6)^{*}$ & 10.9 (2.6) \\
\hline & Avian blood & $14.3(2.5)^{*}$ & $37.3(5.2)^{*}$ & $9.7(4.4)$ \\
\hline & Water control & $3.9(1.4)$ & 9.7 (2.6) & - \\
\hline
\end{tabular}

*Means statistically significant from corresponding water control at the $P=0.05$ level, (paired t-test).

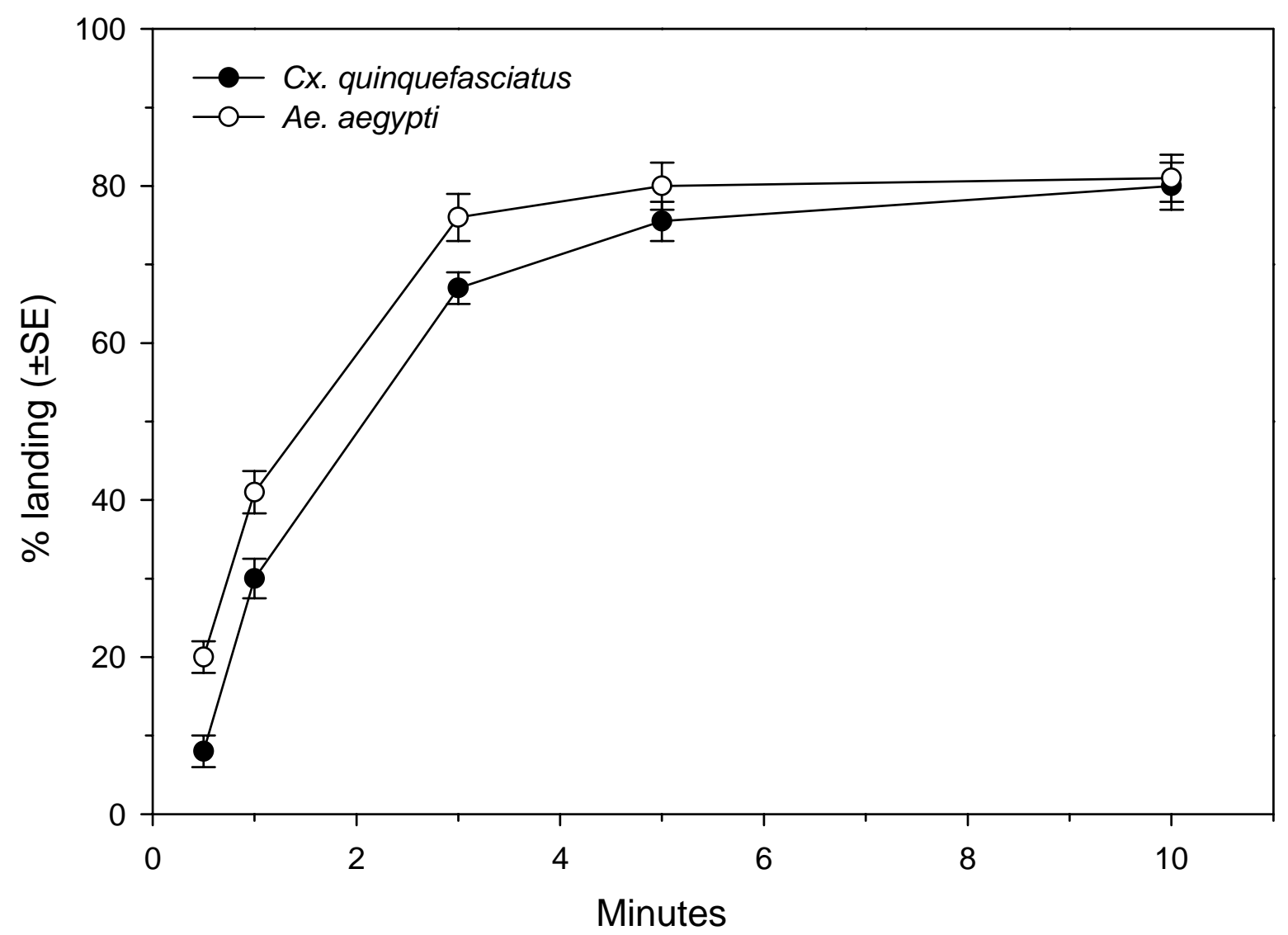

Figure 1. Landing responses of females over time on collagen casings filled with bovine blood $(\mathrm{N}=10)$. 
Table 3. Responses of host-seeking mosquitoes in olfactometer assays to volatile compounds associated with blood. All treatments were tested against a water control. Assays were $15 \mathrm{~min}$ in duration and replicated six times.

\begin{tabular}{llll} 
& \multicolumn{3}{c}{ Mean \% of mosquitoes in treatment port (SE) } \\
\cline { 2 - 4 } Controls & Ae. aegypti & Cx. quinquefasciatus & Cx. nigripalpus \\
$\quad$ Bovine blood & $58.4(3.3)^{*}$ & $38.3(6.6)^{*}$ & $13.0(1.4)^{*}$ \\
Water & $12.0(2.5)$ & $3.7(0.9)$ & $0.2(0.2)$ \\
Acids & & & \\
Acetic acid & $18.5(2.4)^{*}$ & $0.0(0.0)$ & $0.3(0.3)$ \\
Butanoic acid & $9.2(1.4)$ & $3.8(0.9)$ & $1.6(1.6)$ \\
Heptanoic acid & $11.7(3.6)$ & $2.5(0.8)$ & $0.3(0.3)$ \\
Lactic acid & $25.2(6.3)^{*}$ & $9.9(2.3)^{*}$ & $0.3(0.3)$ \\
3-methyl butanoic acid & $6.5(1.9)$ & $5.5(2.2)$ & $0.0(0.0)$ \\
Myristic acid & $3.5(1.0)$ & $0.8(0.6)$ & $3.6(1.5)^{*}$ \\
Palmitic acid & $5.8(2.1)$ & $3.0(1.9)$ & $0.6(0.6)$ \\
Propionic acid & $3.4(0.9)$ & $0.7(0.4)$ & $0.0(0.0)$ \\
Stearic acid & $5.9(2.7)$ & $6.8(2.0)$ & $0.0(0.0)$ \\
& & & \\
Sulfides & & & $1.3(0.5)$ \\
Carbon disulfide & $17.7(4.6)^{*}$ & $0.4(0.4)$ & $3.2(1.4)^{*}$ \\
Dimethyl disulfide & $37.2(9.1)^{*}$ & $5.2(2.4)$ & $1.2(0.3)$ \\
Dimethyl trisulfide & $4.4(0.3)$ & $0.6(0.2)$ & $0.3(0.3)$ \\
Ethyl disulfide & $2.4(0.9)$ & $4.9(1.0)$ & $2.3(0.3)^{*}$ \\
Methyl propyl disulfide & $2.1(2.1)$ & $3.1(0.8)$ & $0.0(0.0)$ \\
Methyl sulfide & $31.7(7.5)^{*}$ & $2.2(1.2)$ & \\
\hline
\end{tabular}

*Means statistically significant from corresponding water control at the $P=0.05$ level, (paired t-test).

mosquitoes (paired t-test, $P>0.05$ ). Landing responses were obtained from all species in response to individual compounds in the assay indicating that this method is effective in evaluation of these responses.

\section{DISCUSSION}

The collagen membrane assay was effective for evaluation of both attraction and landing responses to blood and to chemical standards. Volatiles from the blood permeated the membranes and provided cues for attraction and landing behaviors. Additionally, these membranes were appropriate for providing standardized heat and moisture cues for testing of individual chemical compounds. In previous studies, collagen membranes were used in artificial feeders to examine landing responses of Aedes aegypti to sweat components and repellents (Cockcroft et al. 1998, Healy and Copland 2000, Healy et al. 2002).

Blood clearly emitted volatiles that elicited attraction in the olfactometer and elicited landing responses. Females Ae. aegypti and $C x$. quinquefasciatus differed in some of their attraction and landing responses to bovine and avian blood. These differences may be due to differences in concentration or composition of a mixture of volatile compounds emitted from these two types of blood. Little is known about the volatile composition of these two blood sources. While reports indicate that there are differences in the abundance of different classes of wax components on the skin between cows and chickens (Nicolaides et al. 1968, Nicolaides et al. 1970), no direct comparisons can be made based on volatiles emitted from blood. Responses of $C x$. nigripalpus were generally low to all treatments and about three to four times lower than those of the other species to bovine blood. The low response may be due to inherent differences in feeding behavior or lack of additional critical attractant stimuli (i.e., $\mathrm{CO}_{2}$ ) for this species. Both types of blood, however, provided volatile cues that elicited attraction of all three species of mosquitoes.

Individual compounds evaluated differed in responses elicited and intensity of response between species. In general, Ae. aegypti females responded more strongly than the Culex females. More compounds elicited significant responses by Ae. aegypti in the landing assays than in the olfactometer assays indicating that these compounds may serve as closerange attractants. Carboxylic acids are common lipid components of mammalian skin and emanations (Nicholaides 1965, Sharaf et al. 1977, Bernier et al. 2002) and several are well-documented as attractants. For instance, lactic acid is a component of sweat found in high levels in humans, moderate levels in other mammals, and low levels in chickens (Dekker et al. 2002). In conjunction with $\mathrm{CO}_{2}$, it is highly attractive to Ae. aegypti (Geier et al. 1996) and An. gambiae (Dekker et al. 2002). Short-chained carboxylic acids were attractive for Ae. aegypti in combination with L-lactic aid (Bosch et al. 2000). However, when Healy and Copland (2000) combined 
Table 4. Responses of host-seeking mosquitoes in cage assays to collagen casings treated with compounds (1 ug) associated with blood. Assays were $5 \mathrm{~min}$ in duration and replicated 10 times.

Mean \% of mosquitoes in treatment port (SE)

\begin{tabular}{llll} 
& Ae. aegypti & Cx. quinquefasciatus & Cx. nigripalpus \\
\hline Controls & & & \\
Bovine blood & $84.0(5.3)^{*}$ & $61.0(4.7)^{*}$ & $24.1(2.7)^{*}$ \\
Water & $12.0(1.4)$ & $3.9(1.6)$ & $1.0(1.0)$
\end{tabular}

Acids

$\begin{array}{llll}\text { Acetic acid } & 18.1(1.2)^{*} & 28.2(6.6)^{*} & 3.2(1.0) \\ \text { Benzoic acid } & 38.4(6.1)^{*} & 0.0(0.0) & 0.0(0.0) \\ \text { Butanoic acid } & 28.5(6.0)^{*} & 1.5(1.1) & 1.1(1.1) \\ \text { Heptanoic acid } & 28.9(3.2)^{*} & 2.8(1.5) & 0.0(0.0) \\ \text { Lactic acid } & 30.7(2.7)^{*} & 1.6(0.8) & 9.0(1.7)^{*} \\ \text { 3-methylbutanoic acid } & 50.8(5.3)^{*} & 0.0(0.0) & 0.0(0.0) \\ \text { Myristic acid } & 33.8(3.4)^{*} & 0.5(0.5) & 0.0(0.0) \\ \text { Palmitic acid } & 65.9(5.6)^{*} & 9.7(1.4)^{*} & 1.3(1.3) \\ \text { Propionic acid } & 6.0(2.2) & 6.1(2.8) & 4.5(1.7) \\ \text { Salicylic acid } & 60.3(5.1)^{*} & 2.1(1.6) & 1.5(1.5) \\ \text { Stearic acid } & 51.7(4.3)^{*} & 23.3(4.5)^{*} & 9.9(2.9)^{*} \\ & & & \\ \text { fides } & & & 1.9(1.0) \\ \text { Carbon disulfide } & 25.2(4.6)^{*} & 1.5(1.0) & 1.7(0.9) \\ \text { Dimethyl disulfide } & 4.0(0.7) & 2.5(0.3) & 11.0(1.0)^{*} \\ \text { Dimethyl trisulfide } & 8.0(2.3) & 8.0(1.8)^{*} & 8.5(2.3)^{*} \\ \text { Ethyl disulfide } & 11.0(2.7) & 6.6(2.3) & 5.0(1.5)^{*} \\ \text { Methyl propyl disulfide } & 18.0(1.1)^{*} & 10.5(1.7)^{*} & 1.4(0.9) \\ \text { Methyl sulfide } & 20.4(3.7)^{*} & 2.7(1.5) & \end{array}$

*Means statistically significant greater than water control at the $P=0.05$ level, (paired t-test).

22 carboxylic acids identified from human sweat, no landing responses were elicited from An. gambiae. Aliphatic carboxylic acids have been reported as attractive for $A n$. gambiae (Knols et al. 1997) and Ae. aegypti (Carlson et al. 1973) and elicit electrophysiological responses (Lacher 1967, Davis 1988, Meijerink and van Loon 1999). In our study individual carboxylic acids elicited moderate attraction in the olfactometer. However, they were very effective at eliciting landing responses from Ae. aegypti, and to a minor extent, in Culex. Future studies will examine combinations of compounds for synergism in attraction.

Sulfide compounds have been reported as components of human skin and emanations (Krotosynski et al. 1977, Bernier et al. 2000) and methyl sulfide has been identified as a component of bovine blood (Bassette et al. 1996). Although reports of mosquito responses to sulfides are limited, Bernier et al. (2003) reported that dimethyl disulfide as a component of human skin emanations synergized attraction of Ae. aegypti to lactic acid. The role of sulfides as attractants for gravid mosquitoes has received attention. Du and Millar (1999) reported electrophysiological and some behavioral responses from gravid $C x$. quinquefasciatus and $C x$. tarsalis to methyl trisulfide. However, subsequent study with gravid Ae. albopictus indicated no electrophysiological or behavioral response to another sulfide, dimethyl disulfide (Trexler et al. 2003). Females of Ae. aegypti responded to carbon disulfide, dimethyl disulfide, and methyl sulfide in both olfactometer and landing assays and these compounds may play a role in host finding in this species. Responses of Culex to sulfides were low but significant and these components may play minor roles in attraction or as a component in an attractive blend of compounds.

Artificial feeding systems for mosquitoes are important for establishment and maintenance of colonies in the absence of vertebrate hosts and for inoculation in disease transmission studies. Females of Culex, however, are considered to be more reluctant to feed on membranes than species such as $A e$. aegypti (Novak et al. 1991). For instance, in this study fewer than $12 \%$ of female $C x$. nigripalpus fed on membranes whether bovine or avian blood was presented. Cosgrove and Wood (1995) suggested that volatile compounds such as those isolated from skin might increase the efficacy of the membrane feeding system and Waladde et al. (1991) used skin extracts to enhance tick feeding on membranes. In addition, shortrange attractants may have potential as trap lure components to enhance collection of mosquitoes as they come in closer proximity to the trap intake. In future studies, volatile compounds from bovine and avian blood will be identified, compared, and evaluated as possible additives for enhancing success with membrane feeding by Culex females and for trap collection enhancement. 


\section{Acknowledgments}

We thank Arikia Millikan, Erin Vrzal, and Ken Posey for assistance with this study and Haze Brown and Aissa Doumbouya for providing mosquitoes.

\section{REFERENCES CITED}

Ashley, D. L., M. A. Bonin, F. L. Cardinali, J. M. McCraw, J. S. Holler, L. L. Needham, and D. G. Patterson, Jr. 1992. Determining volatile organic compounds in human blood from a large sample population by using purge and trap gas chromatography/mass spectrometry. Analyt. Chem. 64: 1021-1029.

Bassette, R., M.E. Turner, and G. Ward. 1966. Volatile compounds in blood, milk, and urine of cows fed silagegrain, bromegrass pasture, and hay-grain test meals. J. Dairy Sci. 49: 811-815.

Bernier, U.R., D.L. Kline, D.R. Barnard, C.E. Schreck, and R.A. Yost. 2000. Analysis of human skin emanations by gas chromatography/mass spectrometry. 2. Identification of volatile compounds that are candidate attractants for the yellow fever mosquito (Aedes aegypti). Analyt. Chem.. 72: 747-756.

Bernier, U. R., D.L. Kline, C.E. Schreck, R.A. Yost, and D.R. Barnard. 2002. Chemical analysis of human skin emanations: Comparison of volatiles from humans that differ in attraction of Aedes aegypti (Diptera: Culicidae). J. Am. Mosq. Contr. Assoc. 18: 186-195.

Bernier, U.R., D.L. Kline, K.H. Posey, M.M. Booth, R.A. Yost, and D.R. Barnard. 2003. Synergistic attraction of Aedes aegypti (L.) to binary blends of L-lactic acid and acetone, dichloromethane, or dimethyl disulfide. J. Med. Entomol. 40: 653-656.

Bonin, M. A., D. L. Ashley, F. L. Cardinali, J. M. McCraw, and D. G. Patterson, Jr. 1992. Importance of enhanced mass resolution in removing interferences when measuring volatile organic compounds in human blood by using purge-and-trap gas chromatogaphy/Mass spectrometry. J. Am. Soc. Mass. Spectrom. 3: 831-841.

Bos, H. J. and J. J. Laarman. 1975. Guinea pig, lysine, cadaverine and estradiol as attractants for the malaria mosquito Anopheles stephensi. Entomol. Exp. Appl. 18: 161-172.

Bosch, O.J., M. Geier, and J. Boeckh. 2000. Contributions of fatty acids to olfactory host finding of females Aedes aegypti. Chem. Senses 25: 323-330.

Brown, A.W.A. and A.G. Carmichael. 1961. Lysine and alanine as mosquito attractants. J. Econ. Entomol. 54: 317-324.

Burgess, L. and A.W.A. Brown. 1957. Studies on the responses of female Aedes mosquito: VIII. The attractiveness of beef blood to Aedes aegypti. Bull. Entomol. Res. 48: 783793.

Carlson, D.A, N. Smith, H.K. Gouck, and D.R. Godwin. 1973. Yellow fever mosquitoes: Compounds related to lactic acid that attract females. J. Econ. Entomol. 66 : 269276.
Clements, A. N. 1999. The Biology of Mosquitoes. Volume 2. Sensory reception and behavior. CABI Publishing, NY.

Cockcroft, A., J.B. Cosgrove, and R.J. Wood. 1998. Comparative repellency of commercial formulations of deet, permethrin and citronellal against the Aedes aegypti, using a collagen membrane technique compared with human arm tests. Med. Vet. Entomol. 12: 289-294.

Cosgrove, J.B., R.J. Wood, D Petric, D.T. Evans, and R.H.R. Abbott. 1994. A convenient mosquito membrane feeding system. J. Am. Mosq. Contr. Assoc. 10: 434-436.

Cosgrove, J.B. and R.J. Wood. 1995. Probing and gorging responses of three mosquito species to a membrane feeding system at a range of temperatures. J. Am. Mosq. Contr. Assoc. 11: 339-342.

Davis, E.E. 1988. Structure-response relationship of the lactic acid-excited neurons in the antennal grooved-peg sensilla of the mosquito Aedes aegypti. J. Insect Physiol. 34: 443449.

Dekker, T., B. Steib, R.T. Cardé, and M. Geier. 2002. L-lactic acid: a human-signifying host cue for the anthropophilic mosquito Anopheles gambiae. Med. Vet. Entomol. 16: 91-98.

Dimond, J.B., A. O. Lea, and D.M. Long. 1956. The amino acids required for egg production in Aedes aegypti. Canad. Entomol. 57-62.

Du, Y. and J.G. Millar. 1999. Electroantennogram and oviposition bioassay responses of Culex quinquefasciatus and Culex tarsalis (Diptera: Culicidae) to chemicals in odors from Bermuda grass infusions. J. Med. Entomol. 36: 158-166.

Friend, W.G. and J.J.B. Smith. 1977. Factors affecting feeding by blood-sucking insects. Annu. Rev. Entomol. 22: 309331.

Friend, W.G. 1978. Physical factors affecting the feeding response of Culiseta inornata to ATP, sucrose and blood. Ann. Entomol. Soc. Am. 7: 935-940.

Galun, R. 1974. Behavioral aspects of chemoreception in blood-sucking arthropods. In: R. Galun, P. Hillman, I. Parnas, and R. Werman (eds.) Sensory Physiology and Behavior. Plenum Press, NY.

Galun, R. 1988. Purigenic reception by culicine mosquitoes. J. Comp. Physiol. (A) 163: 665-670.

Geier, M., H. Sass, and J. Boeckh. 1996. A search for components in human body odour that attract females of Aedes aegypti. Olfaction in Mosquito-Host Interactions (ed. by G. Cardew), pp. 132-144. Ciba Foundation Symposium no. 200. John Wiley \& Sons, Chichester.

Gerberg, E.J., D.R. Barnard, and R.A. Ward. 1994. Manual for mosquito rearing and experimental techniques. Am. Mosq. Contr. Assoc. Bull. No. 5. 102 pp.

Healy, T.P. and M.J.W. Copland. 2000. Human sweat and 2oxopentanoic acid elicit a landing response from Anopheles gambiae. Med. Vet. Entomol. 14: 195-200.

Healy, T.P., M.J.W. Copland, A. Cork, A. Przyborowska, and J.M. Halket. 2002. Landing responses of Anopheles gambiae elicited by oxocarboxylic acids. Med. Vet. Entomol. 16: 126-132.

Hosoi, T. 1959. Identification of blood components which 
induce gorging in the mosquito. J. Insect Physiol. 3: 1919218.

Issachar, D., J.F. Holland, and C.C. Sweley. 1982. Metabolic profiles of organic acids from human plasma. Analyt. Chem. 54: 29-32.

Khan, A.A. 1977. Mosquito attractants and repellents.. In: H.H. Shorey and J.J. McKelvey, Jr. (eds.) Chemical control of insect behavior. pp. 305-325. Wiley and Sons, NY.

Knols, B.G.J., J.J.A. van Loon, A. Cork, R.D. Robinson, W. Adam, J. Meijerink, R. DeJong, and W. Takken. 1997. Behavioral and electrophysiological responses of the female malaria mosquito Anopheles gambiae (Diptera: Culicidae) to Limburger cheese volatiles. Bull. Entomol. Res. 87: 151-159.

Krotoszynski, B., G. Gabriel, and H. O’Neill. 1977. Characterization of human expired air: a promising investigative and diagnostic technique. J. Chrom. Sci. 15: 239-244.

Lacher, V. 1967. Elektrophysiologische untersuchengen an einzelnen geruchsrezeptonen auf den antennen weiblicher moskitos (Aedes aegypti L.) J. Insect Physiol. 64: 313314.

Lipsitz, E.Y. and A.W.A. Brown. 1964. Studies on the responses of the female Aedes mosquito. IX. The mode of attractiveness of lysine and other amino acids. Bull. Entomol. Res. 54: 675-687.

Meijerink, J. and J.J.A. van Loon. 1999. Sensitivities of antennal olfactory neurons of the malaria mosquito, Anopheles gambiae, to carboxylic acids. J. Insect Physiol. 45: 365-373.

Müller, W. 1968. Die distanz- undkontakt-orientierung der stechmücken (Aedes aegypti) (Wirtzfindung, Stechnerhalten und blutmahlzeit). Z. vergl. physiol. 58: 241-303.

Nicolaides, N. 1965. Skin Lipids. II. Lipid class composition of samples from various species and anatomical sites. J. Am. Oil Chem. Soc. 42: 691-702.

Nicolaides, N., H. C. Fu, and G.R. Rice. 1968. The skin surface lipids of man compared with those of eighteen species of animals. J. Invest. Dermatol. 51: 83-89.

Nicolaides, N., H.C. Fu, and M.N.A. Ansari. 1970. Diester waxes in surface lipids of animal skin. Lipids 5: 299307.

Novak, M.G., W.J. Berry, and W.A. Rowley. 1991. Comparison of four membranes for artificially bloodfeeding mosquitoes. J. Am. Mosq. Contr. Assoc. 7: 327-329.

Posey, K. H. and C. E. Schreck. 1981. An airflow apparatus for selecting female mosquitoes for use in repellent and attraction studies. Mosq. News 41: 566-568.

Posey, K. H., D. R. Barnard, and D. E. Schreck. 1998. Triple cage olfactometer for evaluating mosquito (Diptera: Culicidae) attraction responses. J. Med. Entomol. 35: 330-334.

Sastry, S. D., K. T. Buck, J. Janak, M. Dressler, and G. Preti. 1980. Volatiles emitted by humans. In: G.R. Waller and O.C. Dremer (eds.). Biochemical applications of mass spectrometry, first supplementary volume. John Wiley and Sons, NY.

Schaerffenberg, B. and E. Kupka. 1959. Der attractive factor des blutes fur blutsagende insekten. Naturwissenschaften 46: 457-458.

Sharaf, D.M., S.J. Clark, and D.T. Cowning. 1977. Skin surface lipids of the dog. Lipids 12: 786-790.

Singh, K.R.P. and D.W. Micks. 1957. Synthesis of amino acids in Aedes aegypti. Mosq. News 17: 248-251.

Trexler, J.D., C.S. Apperson, C. Gemeno, M.J. Perich, D. Carlson, and C. Schal. 2003. field and laboratory evaluations of potential oviposition attractants for Aedes albopictus (Diptera: Culicidae). J. Am. Mosq. Contr. Assoc. 19: 228-234.

Waladde, S.M., S.A. Ochieng, and P.M. Gichuchi. 1991. Artificial-membrane feeding on the ixodid tick, Rhipicephalus appendiculatus, to repletion. Exp. Appl. Acarol. 11: 297-306.

Wirtz, R.A. and L. C. Rutledge. 1980. Reconstituted collagen sausage casing for blood feeding of mosquitoes. Mosq. News 40: 287-288. 